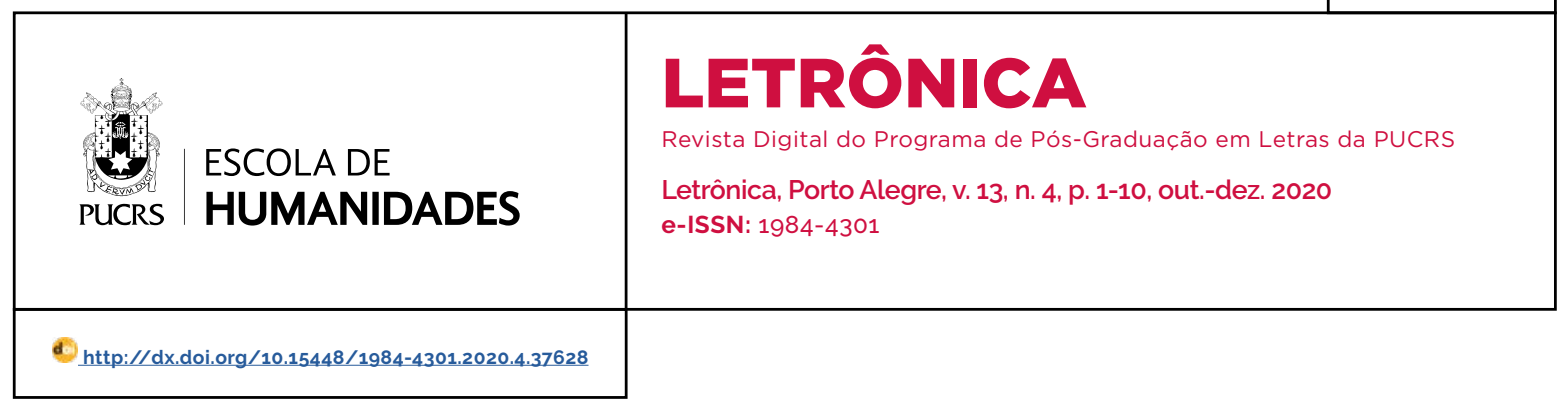

SEÇÃO: ARTIGOS

\title{
Um estudo sobre o percurso de leitura em ambiente digital ${ }^{1}$
}

\author{
A study on the reading path in a digital environment
}

Kári Lúcia Forneck ${ }^{2}$ orcid.org/0000-0001-5906-4269

kari@univates.br

\section{Silvana Neumann}

Martins $^{2}$

orcid.org/0000-0003-1944-3760

smartins@univates.br

\section{Carolina Taís Werlang ${ }^{2}$}

orcid.org/0000-0002-2503-777X

carolina.werlang@univates.br

Róger Sullivan Faleiro ${ }^{2}$

orcid.org/0000-0003-4136-839X rsfaleiro@universo.univates.br

Pâmela Lopes Vicari³ orcid.org/0000-0002-3607-500X pamelavicari1@gmail.com

\section{Keylliane de Sousa \\ Martins $^{2}$}

orcid.org/0000-0001-8531-6482 keylliane.martins@ifma.edu.br

Recebido em: 12/4/2020 Aprovado em: 22/6/2020. Publicado em: 21/12/2020.

\section{(c) (i)}

Artigo está licenciado sob forma de uma licença Creative Commons Atribuição 4.0 Internacional.
Resumo: Este estudo se fundamenta no campo teórico dos estudos da compreensão leitora (MORAIS, 2013; KINTSCH; RAWSON, 2013; PERFETTI; LANDI; OAKHILL, 2013), que se concretiza por meio do uso de estratégias de leitura (SOLÉ, 1998; MORAES, 2014: PEREIRA, 2012). O estudo teve como objetivo investigar quais estratégias de leitura são mobilizadas por estudantes durante a interação com um objeto digital de aprendizagem. Para tanto, participaram da ação dez estudantes do Ensino Fundamental, de uma escola pública do municipio de Lajeado, RS, que tiveram sua interação com o objeto gravada por meio de captura de tela com o software de screencast CamStudio, a fim de se identificar as particularidades de seu percurso de leitura durante a interação. Observou-se que a maioria dos alunos lê linearmente até alcançar seu objetivo de leitura, ou seja, até solucionar a questão; depois disso, saltam pelo texto e ignoram seu conteúdo. Participantes que optaram por realizar saltos entre as linhas demonstraram dificuldade, tornando-se necessário realizar retomadas com o objetivo de reler tanto o enunciado quanto partes do texto para resolver a questão. Ainda, verificou-se que os estudantes não leram os feedbacks interativos disponiveis na plataforma.

Palavras-chave: Estratégias de leitura. Compreensão leitora. Objeto digital de aprendizagem. Captura de tela.

Abstract: This study is based on the theoretical field of reading comprehension studies (MORAIS, 2013; KINTSCH; RAWSON, 2013; PERFETTI; LANDI; OAKHILL, 2013). which is realized through the use of reading strategies (SOLÉ, 1998; MORAES, 2014: PEREIRA, 2012). The study aimed to investigate which reading strategies are mobilized by students during the interaction with a digital learning object. For this purpose, ten elementary school students from a public school in the city of Lajeado/RS participated in the action. Their interaction with the object was recorded through screen capture with the screencast software CamStudio, in order to identify the particularities of your reading path during the interaction. It was observed that most students read linearly until they reach their reading objective, that is, until they resolve the question; after that, they jump through the text and ignore its content. Participants who chose to make jumps between the lines showed difficulty, making it necessary to perform retakes in order to reread both the statement and parts of the text to resolve the task. Still, it was found that students did not read the interactive feedbacks available on the platform.

Keywords: Reading strategies. Reading comprehension. Digital learning object. Print screen.

\section{Introdução}

Ainda que questionáveis, os processos avaliativos em larga escala revelam um abismo entre o conhecimento produzido acerca do processamento da compreensão e as práticas de ensino que resultem em efetiva aprendizagem da leitura.

\footnotetext{
Pesquisa financiada pela Fundação de Amparo à Pesquisa do Estado do Rio Grande do Sul (Fapergs).

Universidade do Vale do Taquari (Univates), Lajeado, RS, Brasil.

Universidade Federal de Santa Catarina (UFSC), Florianópolis, SC, Brasil.
} 
Conforme as informações divulgadas no último relatório do Programa Internacional de Avaliação de Estudantes (PISA) (BRASIL, 2018), o desempenho em leitura dos alunos brasileiros está abaixo da média dos alunos dos demais países participantes da Organização para Cooperação e Desenvolvimento Econômico (OCDE) - 413 pontos comparados à média de 487 pontos. E, caso olhemos mais atentamente para esses dados, veremos que $74,6 \%$ dos estudantes brasileiros estão distribuidos entre os niveis $1 c$ e 2, em uma escala de 1(1a, 1b e 1c) a 6.

Diante de um cenário complexo no qual se entrecruzam estudos sobre processamento da leitura, metodologias de ensino da leitura e desempenho em leitura, desde 2014, o grupo de pesquisa "Um click na leitura" articula produção de objetos digitais de aprendizagem e práticas pedagógicas com o uso da tecnologia a fim de desenvolver, no ambiente escolar, habilidades de leitura. Essas ações iniciaram quando o grupo ainda estava vinculado a um projeto de extensão, denominado "O ensino de estratégias de leitura: propostas de intervenção por meio de objetos virtuais de aprendizagem" cujas atividades foram desenvolvidas pelo curso de Letras da Univates em parceria com o Laboratório de Aprendizagem (Unipren), e resultaram em objetos digitais de aprendizagem (ODA). 5 Em 2016, o grupo fez parte do projeto de extensão "Veredas da Linguagem", no eixo "Linguagem e Cognição", no qual se buscava auxiliar alunos e professores na identificação precoce de dificuldades de aprendizagem da leitura através de intervenções pedagógicas. Atualmente, as práticas de pesquisa vêm sendo desenvolvidas no escopo do projeto de trabalho "Um click na leitura: objetos virtuais de compreensão textual" (Auxilio Recém-Doutor/Fapergs) com a finalidade de potencializar habilidades metacognitivas de leitura relacionadas à compreensão.

Neste texto, intencionamos relatar uma das etapas da pesquisa que teve como objetivo examinar quais são as estratégias de leitura utilizadas por estudantes do Ensino Fundamental (EF), enquanto manipulam um dos objetos digitais de aprendizagem produzidos. Para tanto, foram gravadas as interações na tela, decorrentes do movimento do cursor do mouse, replicando um estudo prévio desenvolvido por Pereira, Baretta e Saraiva (2017).

Em um primeiro momento, contextualizamos o ponto de vista teórico deste trabalho através da menção a estudiosos que versam sobre como a leitura é realizada a partir de uma perspectiva cognitiva. Em seguida, apresentamos, em linhas gerais, a intervenção pedagógica com alunos de $7 .^{\circ}$ ano do EF que resultou na produção do material de análise e, por fim, realizamos a análise dos dados, gerados por um software de screencast, conforme a performance dos participantes.

\section{Considerações teóricas}

Além do baixo rendimento dos estudantes no Programa Internacional de Avaliação de Estudantes (Pisa), a Prova Brasil também confirma as dificuldades dos alunos brasileiros em resolverem questões relacionadas à lingua portuguesa. No Rio Grande do Sul, estado em que se desenvolve esse projeto, a média do Índice de Desenvolvimento da Educação Básica (ldeb) ${ }^{6}$ dos anos finais do Ensino Fundamental é de 3,8 a 4,6, em um indicador que varia de 0 a 10 pontos, permanecendo nesse nivel de 2005 até 2017, ano em que foi divulgado o último resultado pelo Instituto Nacional de Estudos e Pesquisas Educacionais Anísio Teixeira (Inep).

Esse desempenho é preocupante, ainda mais considerando-se que já temos à disposição um conjunto robusto de estudos que vêm reforçando a importância da leitura para, inclusive, garantir que os sujeitos possam interagir em uma sociedade letrada (BEDDINGTON et al., 2008). Todavia, ressalta-se que a habilidade de ler necessita ser desenvolvida constantemente, já que "ser letrado hoje não é garantia de que seremos letrados amanhã" (ZACHARIAS, 2016, p. 17).

Partindo dessa premissa, é importante que a escola, como ferramenta fundamental para o

\footnotetext{
5 Repositório de Objetos de Aprendizagem da UNIVATES (ROAU). Disponivel em: www.univates.br/roau. Acesso em: 27 jul. 2020.

6 O Ideb é calculado a partir de dois componentes: a taxa de aprovação e o desempenho em avaliações de larga escala, como a Prova Brasil. Os dados apresentados estão disponiveis no Resumo Técnico (INEP, 2017).
} 
desenvolvimento de sujeitos leitores, promova atividades que aliem a leitura à construção do sujeito enquanto ser cultural e social. Entretanto, o que se percebe na realidade escolar é o desenvolvimento de atividades limitadas à recuperação dos elementos explicitos presentes na superficie do texto, incapazes, assim, de provocar a compreensão das múltiplas funções da leitura.

No desenho de nossas atividades de pesquisa, assumimos o saber ler não apenas com a visão restrita de que ler é simplesmente decodificar, mas como resultado da interação entre o leitor e o texto (ZACHARIAS, 2016). Por decodificação, processo fundamental para a leitura, entende-se a competência de identificar unidades ortográficas, transformá-las em unidades fonológicas e uni-las ou combiná-las entre si (MORAIS, 2013). Já a compreensão, exige outras habilidades, mais complexas, que resultem na produção de sentido ao conteúdo do texto que atenda aos propósitos de leitura. Afinal, o "objetivo da leitura é compreender o que se lê" (MORAIS, 2013, p. 74).

Portanto, fundamentamos nosso estudo a partir da concepção de leitura sob a perspectiva da compreensão, tal como defendida por Morais (2013, p. 111):

[...] a compreensão de um texto refere-se à elaboração progressiva de uma representação mental integrada nas informações apresentadas sucessivamente no texto, de tal maneira que os objetivos do seu autor sejam corretamente apreciados.

Assim, no decurso da leitura, as informações devem ser processadas - redesenhadas, confirmadas ou refutadas -, de modo que se alcancem os objetivos de leitura previamente estabelecidos pelo leitor. Ou seja, qualquer pessoa que tenha aprendido a ler deve ter "adquirido um sistema mental de processamento de informações capaz de realizar essas transformações" (COLTHEART, 2003, p. 24).

E mais: bons leitores devem ser aptos a monitorar o percurso da compreensão, a fim de construirem sua representação mental que contenha o modelo situacional (KINTSCH; RAWSON, 2013), de modo consciente e automonitorado. Se a compreensão não for satisfatória, o leitor deve ser capaz de avaliar em que momento a rota de leitura foi quebrada para, assim, retornar e fazer ajustes necessários ao curso da compreensão (PERFETTI; LANDI; OAKHILL, 2013).

Além disso, para compreender o texto e para resolver os objetivos da leitura, o leitor se utiliza de estratégias que definem o percurso que será desenhado para que a compreensão se concretize. Segundo Solé (1998), as estratégias de compreensão leitora nem sempre são conscientes, mas já sabemos que leitores hábeis têm mais facilidade em acessar diferentes estratégias no decurso da leitura, a depender do contexto em que essa compreensão é requerida. Conforme Morais (2013), sua escolha pode variar conforme o objetivo da leitura e pode ser tensionada por critérios de tempo e de dificuldade. Ademais, as estratégias de leitura auxiliam o leitor "a selecionar, avaliar, persistir, abandonar ou alterar hipóteses que ele vai criando sobre o conteúdo que está lendo" (PEREIRA; BARETTA; SARAIVA, 2017, p. 121), como, por exemplo, grifar palavras relevantes, escrever pequenos comentários, criar mapas mentais, sumarizar o que foi lido e "inferir os significados de palavras desconhecidas a partir do texto" (PERFETTI; LANDI; OAKHILL, 2013, p. 258).

Dentre as diferentes estratégias ativadas no processo da leitura, optou-se pela escolha das estratégias de skimming e de scanning para subsidiar esse estudo, já que tais habilidades são mais discerniveis na análise do movimento de mouse durante a interação com o objeto.

Antes de as conceituarmos, vale ressaltar que, além das estratégias de leitura skimming e scanning, há outras definições de estratégias de leitura comumente referenciadas em estudos sobre o processamento da compreensão. Duas delas, por exemplo, correspondem às estratégias top-down e bottom-up. Neste estudo, entretanto, não nos deteremos na discussão das diferenças conceituais entre elas.

A estratégia de skimming, conforme Moraes (2014, p. 35), "deriva do verbo TO SKIMM que significa desnatar (o leite), tirar da superfície". Essa estratégia é utilizada para encontrar a ideia central do texto, a partir de uma visão global do instrumento lido. A autora defende que a utili- 
zação de skimming "permite ao leitor identificar rapidamente a ideia principal ou sentido do texto. Por ser mais abrangente, exige conhecimento de organização de texto" (MORAES, 2014, p. 36).

Isso se evidencia quando o aluno utiliza seu mouse através de saltos, ${ }^{7}$ a fim de buscar a ideia principal do texto. Conforme Leffa (1996, p. 67), "os olhos não deslizam em movimento uniforme sobre o texto, mas avançam pulando de um ponto a outro". Nesse sentido, alunos que utilizarem essa estratégia podem realizar saltos em quantidades diferentes, dependendo da sua proficiência em leitura, do seu nivel de habilidade e da sua maestria em identificar as informações centrais.

Já a estratégia de scanning configura-se como uma leitura que busca informações precisas (KOL; SCHCOLNIK, 2000; KRATOCHVIL, 2009). Por isso, "seria uma leitura mais vagarosa e cuidadosa. Em um texto, por exemplo, seria a leitura dos parágrafos buscando a ideia principal de cada um deles" (MORAES, 2014, p. 47). Dessa forma, o leitor necessita ter em mente, durante o uso dessa estratégia, que busca informações úteis a fim de melhorar a sua compreensão sobre o que está sendo lido (PEREIRA; SANTOS, 2017).

Autilização da estratégia scanning é identificada, nessa pesquisa, quando o aluno, durante a interação com o objeto, ler de forma linear, ${ }^{8}$ ou seja, o seu cursor de mouse se movimentará seguindo palavra por palavra, linha por linha. Assim, demonstra que está realizando uma leitura detalhada e não global.

Salienta-se que uma estratégia não anula a outra, visto que alguns leitores podem utilizar ambas para obter sua compreensão do mesmo texto, o que dependerá de seus conhecimentos prévios e objetivos de leitura.

Para o estudo que se relata neste texto, assumimos essas premissas conceituais. A seguir, explicaremos como se desenhou o experimento para, em seguida, apresentarmos os resultados e as discussões desenvolvidas.

\section{Desenho do experimento}

O experimento aqui relatado é parte de um conjunto de ações de pesquisa nas quais se intenciona avaliar o impacto da resolução de atividades de compreensão leitora - elaboradas pelo grupo e disponiveis em um repositório digital, conforme mencionado na introdução - que têm como caracteristica fundamental o feedback instrutivo. O propósito do feedback é trazer para o plano da consciência o percurso trilhado: a) no caso do acerto, para a compreensão; ou b) no caso do erro, para ajustar a leitura à compreensão. Essa abordagem se baseia na concepção de que a compreensão leitora pode ser potencializada por meio do desenvolvimento de estratégias de leitura em nivel metacognitivo (FORNECK; FUCHS; BERSCH, 2015).

A coleta de dados foi realizada simultaneamente ao desenvolvimento de uma oficina que consistiu na aplicação de uma transposição didática envolvendo os objetos digitais de aprendizagem produzidos pelo grupo "Um click na leitura". Essa oficina contou com a participação de três turmas de uma escola pública, totalizando 64 participantes de $7 .^{\circ}$ ano do Ensino Fundamental, e ocorreu no laboratório de informática da Universidade do Vale do Taquari (Univates), Lajeado, RS. A partir da temática variação linguistica, realizou-se um conjunto de atividades que variou entre a apresentação por parte dos ministrantes de curiosidades acerca da riqueza dialetal do Brasil, a apresentação de vídeos, a interação com jogos virtuais e a manipulação dos objetos digitais de aprendizagem produzidos pelo grupo.

Posteriormente, os estudantes foram apresentados ao objeto digital "A língua que falamos" unidade pertencente ao Repositório de Objetos de Aprendizagem Univates (ROAU). 
Figura 1 - Tela de apresentação da atividade interativa

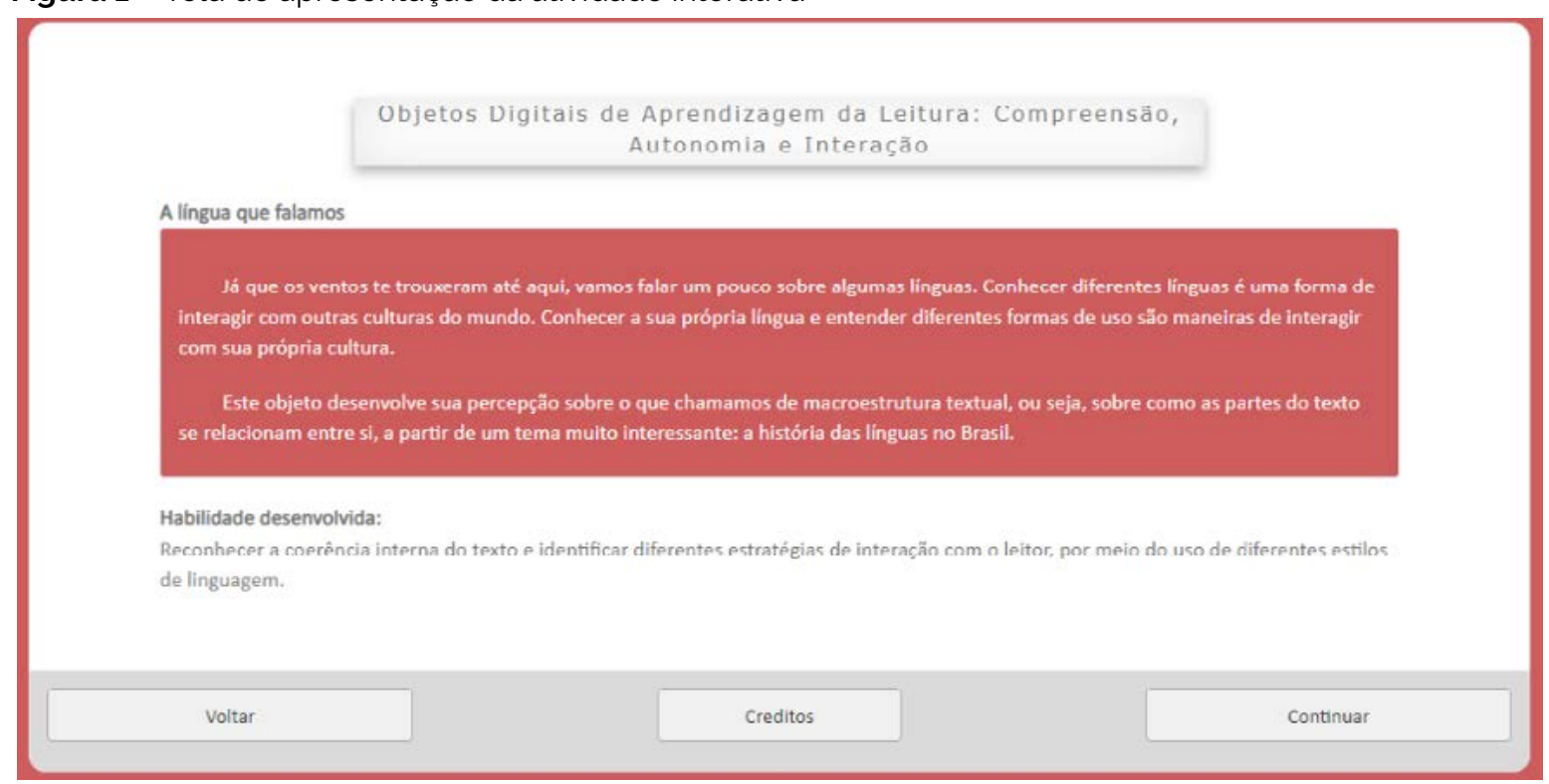

Fonte: ROAU (2020).

O objeto, como visto na Figura 1, apresenta uma tela inicial que consiste em uma apresentação breve do tema e do objetivo que está sendo almejado com o objeto, assim como as habilidades especificas que serão desenvolvidas ao longo das atividades. Em cada tela, o participante pode, quando necessário, clicar na tecla "Voltar" para retomar/reler o conteúdo anterior ou "Avançar" para o próximo exercício.

Durante a interação com o objeto, os alunos responderam a questões optativas relativas ao conteúdo e, ao fim de cada exercício, receberam um feedback de acordo com a resposta. Caso a resposta fosse incorreta, a interação os orientava com dicas para melhorarem sua compreensão e para resolverem o problema em questão. Caso a resposta fosse positiva, lhes informava o acerto e disponibiliza outras instruções para refletirem sobre sua compreensão. O objetivo do retorno é essencial para subsidiar e retroalimentar o processo de interação dos participantes, orientando-os ao alcance dos objetivos traçados, como também envolvendo-os na construção de sua aprendizagem (ALVES; TEIXEIRA, 2014).

A seguir, apresentamos exemplos de feedback para o erro (Figura 2) e de feedback para o acerto da atividade (Figura 3). Ambas as figuras contêm retornos interativos das questões pertencentes ao Objeto Digital de Aprendizagem "A língua que falamos".

Figura 2 - Feedback negativo

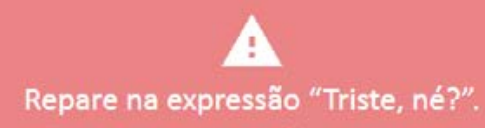

Essa passagem faz com que o leitor reflita sobre o conteúdo apresentado até então e mantenha o interesse no conteúdo que virá. $O$ uso de expressões desse tipo ao longo do texto aproxima o leitor das intenções do autor. A alternativa que você assinalou não apresenta esse recurso. Tente novamente.

Fonte: ROAU (2020). 
Figura 3 - Feedback positivo

\section{FANTÁSTICO}

Você percebeu que o uso da expressão "você deve estar se perguntando" é uma forma de convidar o leitor a refletil sobre o conteúdo que foi apresentado até então e manter a atenção nas informações que virão.

Continuar

Fonte: ROAU (2020).

Do conjunto de alunos que participaram das oficinas, foram recrutados dez alunos voluntários, de forma aleatória, que consentiram em participar de uma segunda etapa de interação, desde que tivessem em mãos o Termo de Consentimento Livre e Esclarecido (TCLE) assinado por seus responsáveis, como exigência para interagirem com o objeto "A língua que falamos", em um outro laboratório, separados do restante. Nesse espaço, os participantes foram orientados, antes da interação, a acompanhar com o cursor do mouse o movimento dos seus olhos durante a leitura e durante a resolução das questões, linha a linha.

Para verificar os detalhes dessa interação, foi utilizado o software de screencast "CamStudio", cuja função é gravar a tela dos computadores e, desse modo, registrar a interação dos participantes. A tela da Figura 4 indica a parte do objeto que foi empregada na gravação.

Figura 4 - Exercício proposto pelo objeto "A lingua que falamos"

\footnotetext{
Você deve ter percebido que a autora do texto, intencionalmente, dialoga com o leitor, na tentativa de estabelecer uma parceria entre autor-texto-leitor.

Repare que hả no texto très passagens em destaque. Clique naquela que contém um exemplo em que se evidencia essa intenção.
}

\section{UM POUCO DA HISTÓRIA DAS LINGUAS NO BRASIL}

Quantas línguas se falam no Brasil? Uma, é claro, o português! Sim, o português é nossa língua oficial. Mas saiba que o Brasil é o oitavo maior país em número de linguas en uso. São mais de 270, segundo o Instituto Brasileiro de Geografia e Estatistica (IBGE), num censo realizado em 2010. Mais precisamente, slo 274 linguas indigenas faladas por individuos de 305 etnias diferentes. A maioria das tribos vive no Norte e no Centro Oeste do Pais, por isso é nessas regiōes que essas línguas predominam.

Você acha que 274 linguas indigenas, alèm do português, é um número elevado? Pode ser, mas, na época do Descobrimento, havia muito, mas muito mais delas! Estima-se que, quando os portugueses apareceram por aqui, cinco milhões de indigenas falavam em torno de 1,2 mil linguas.

Por que diminuiu tanto? Vocè deve estar se perguntando. O linguista Aryon Rodrigues, da Universidade de Brasilia (UnB), explica que essa reduçăo drástica de linguas indigenas faladas nos últimos 500 anos foi o efeito de um processo colonizador extremamente violento e continuado e que ainda permanece. E o pior, elas tendem a diminuir cada vez mais. Para Rodrigues, $87 \%$ delas estão ameaçadas de "morte", ou seja, cada vez menos os indios falam suas linguas de origem, pois precisam do portuguê para comunicar com a sociedade brasileira, para reivindicar seus direitos. Triste, né? Quando uma lingua morre, todo um conjunto de conhecimentos adquiridos por um povo desaparece e o mundo fica mais pobre.

Fonte: ROAU (2020).

Os movimentos do cursor dos dez participantes foram classificados em quatro tipos, sendo eles: leitura linear - momento em que os alunos leem detalhadamente, movimentam o cursor no decorrer das linhas, sem interrupções, paradas ou saltos; momento estático - momento em que os alunos pausam sua leitura; o mouse não se movimenta; retomada - momento em que os alunos releem; o mouse volta para linhas anteriores; e salto - momento em que os alunos desconsideram uma parte da leitura e vão para outra; o mouse pula em meio as linhas. Essa classificação foi inspirada no experimento desenvolvido por Pereira, Baretta e Saraiva (2017), como já mencionamos anteriormente, e está explicitada na Tabela 1 apresentada na seção seguinte.

Com a gravação das telas, foram verificadas quais as estratégias utilizadas pelos estudantes e o tempo 
destinado a cada uma delas, a fim de associar a duração de cada movimento ao desempenho dos participantes na resolução das questões.

A seguir, apresentam-se os resultados e as discussões decorrentes das análises dos achados.
Com o objetivo de ilustrar os dados coletados a partir do conteúdo e analisar se a duração de momentos específicos pode influenciar na resolução de questões de compreensão textual, criou-se a Tabela 1 (doravante S1 para Sujeito 1 , S2 para Sujeito 2, e assim por diante).

\section{Resultados e análises}

TABELA 1 - Classificação do tempo cronometrado utilizado pelos participantes

\begin{tabular}{|c|c|c|c|c|c|}
\hline \multirow{2}{*}{ Sujeito } & \multicolumn{4}{|c|}{ Tempo } & \multirow{2}{*}{ Tentativas } \\
\hline & Linear & Estático & Retomada & Salto & \\
\hline S1 & 20,39 & 16,11 & 0 & 6,4 & 1 \\
\hline $\mathrm{S} 2$ & 29,58 & 2,96 & 20,69 & 14,25 & 3 \\
\hline $\mathrm{S} 3$ & 15,31 & 6,49 & 0 & 10,93 & 1 \\
\hline $\mathrm{S}_{4}$ & 18,28 & 4,09 & 2,1 & 11,56 & 1 \\
\hline $\mathrm{S} 5$ & 30,83 & 15,37 & 0 & 8,19 & 1 \\
\hline S6 & 88,19 & 0 & 3,89 & 13,14 & 1 \\
\hline S7 & 32,94 & 13,16 & 4,76 & 11,51 & 1 \\
\hline S8 & 20,79 & 2,38 & 2,76 & 7.57 & 3 \\
\hline Sg & 15,41 & 1,19 & 6,01 & 6,65 & 1 \\
\hline $\mathrm{S} 10$ & 44,25 & 0 & 1,4 & 1,25 & 1 \\
\hline SOMA & 315,97 & 61,75 & 41,61 & 91,45 & - \\
\hline
\end{tabular}

Fonte: Elaborada pelos autores (2020).

Como se depreende da Tabela 1, foram analisados os desempenhos individuais de cada participante baseados nos movimentos do cursor do mouse. Também, foi possivel tecer algumas considerações acerca do comportamento de leitura desses sujeitos e sobre as estratégias de leitura adotadas por eles na resolução da atividade.

Na resolução da tarefa, o S1 lê o enunciado e o primeiro parágrafo linearmente. No entanto, quando chega à frase correta, salta o texto e clica na alternativa. Na sequência, avança no "Verificar" e recebe o feedback correto, ignorando-o e seguindo para a próxima atividade.

O S2 assume um outro comportamento. Ele salta constantemente entre as linhas do instrumento e retoma diversas vezes o enunciado. Com isso, presume-se que tem como finalidade compreen- der ou relembrar o objetivo de leitura. Ainda, ele não mantém uma leitura linear e erra a questão, refazendo-a três vezes. Embora o sujeito apresente erros consecutivos, ele não lê o feedback.

S5 lê o enunciado e o primeiro parágrafo linearmente. Retoma duas vezes as últimas linhas do primeiro parágrafo e, logo em seguida, se mantém estático por 15.37 segundos. Em sequência, clica na próxima frase e a verifica como correta. Nesse caso, pode-se inferir que, durante o momento estático, o participante lê o conteúdo, mas não acompanha com o cursor o movimento de seus olhos. O sujeito não lê o feedback e avança para as próximas atividades.

Assim como S5, S6 lê o enunciado e o primeiro parágrafo linearmente. Porém, diferente do sujeito anterior, ele retoma para o enunciado, segue len- 
do o segundo parágrafo e lê até o final do texto de forma linear. Ao terminar a leitura do texto, o participante retoma novamente o enunciado e marca a questão correta. Ignora o feedback e continua a resolução das próximas questões.

Os S3, S4, S7, S9 e S10 assumem um comportamento semelhante. Os cinco sujeitos leem o enunciado e direcionam seu cursor para as frases grifadas no texto, sem lerem o texto na integra. Assim, leem as três opções, clicam na correta e verificam. Em relação à leitura do feedback, S7 se mantém estático com tempo suficiente para ler o retorno disponivel na interação, e os S3, S4, S9 e S10 não leem o texto do feedback. Nesse caso, parece-nos que esses sujeitos assumem como objetivo de leitura responder à tarefa do enunciado, sem se deter na leitura do texto. Parecem supor que a resolução da tarefa não requer a compreensão do texto, o que, de fato, ficou evidente pelo acerto na questão e pelo total desinteresse na leitura do feedback.

S8 lê o enunciado, faz a leitura linear do primeiro parágrafo e retoma novamente o enunciado, a fim de compreender o que a atividade propõe. Em seguida, relê a primeira alternativa três vezes, e salta para as próximas frases optativas. Dentre elas, opta pela terceira alternativa e verifica. A resposta está incorreta e, por isso, o sujeito recebe o feedback negativo, ele o lê e volta para o instrumento. O participante inicia novamente a leitura linear do enunciado, escolhe a primeira frase e verifica. Outra vez, marca a alternativa incorreta. Dessa forma, volta para o texto e escolhe a última opção; então, lê o feedback assertivo e clica em continuar para resolver as próximas questões.

Em relação aos comportamentos dos participantes, percebemos que a metade dos leitores, após compreender o objetivo da atividade descrito no enunciado, a metade se utiliza das estratégias de skimming para alcançar a alternativa correta. Cronologicamente, inicia uma leitura detalhada, scanning, linha a linha, mas, logo que assimila as primeiras informações, faz saltos em busca da resposta. Ou seja, utiliza a estratégia de leitura skimming transformando os enunciados lidos em tópicos conceituais - marcas de organização - para construir inferências e percepções a fim de alcançar um entendimento geral sobre o texto (PEREIRA, 2012). Como o uso de uma estratégia de leitura não elimina a utilização de outra, metade dos participantes ora usa a leitura scanning, ora a skimming, a depender de seus propósitos de leitura.

Como se pode ver na Tabela 1, a leitura linear - scanning - somou mais tempo na realização da tarefa. Poderiamos, de imediato, supor que a leitura detalhada é a estratégia mais utilizada para a realização da tarefa de compreensão da atividade do objeto digital. Contudo, se acompanharmos os movimentos do cursor de cada participante, veremos que uma vez que parte do texto foi lida, iniciavam-se os saltos com o cursor em busca da resposta. Ou seja, o comportamento de leitura dos sujeitos revela que a leitura do texto só é feita se, de fato, for necessária à realização da atividade. Caso intuíssem não ser necessário ler todo o texto para realizar a tarefa, os sujeitos iniciavam saltos com o curso do mouse em busca do conteúdo especíico da resposta da tarefa.

Também verificamos que os participantes que optaram em realizar saltos entre as linhas demonstraram dificuldade, tornando-se necessário realizar retomadas com o objetivo de reler tanto o enunciado, quanto partes do texto para resolver a questão.

Além disso, podemos tecer algumas considerações relacionadas à organização do instrumento. Por exemplo, o enunciado da atividade propõe apenas ao leitor que "Repare que há no texto três passagens em destaque" e clique naquela que contém um exemplo da estrutura linguística requerida no enunciado. Ou seja, o próprio enunciado do instrumento não solicita que o participante faça a leitura do texto. Em vista disso, acreditamos que a falta desse comando contribua para a não leitura de todo o texto presente na atividade selecionada como instrumento de testagem, visto que apenas um dos participantes leu o conteúdo por completo. Em nosso entender, a instrução dada nessa atividade pode ter resultado em um comportamento de leitura que induziu os participantes a desconsiderar o texto na integra.

Some-se a isso outra questão: a desconsideração dos feedbacks instrutivos. Se eliminarmos a 
suposta leitura do S7 quando recebeu o feedback, apenas S8 leu e interagiu com o texto contido nessa ferramenta. Todos os outros ignoraram a leitura e passaram para a próxima atividade. Há uma série de conjecturas que podem justificar esse comportamento. Entre elas, as experiências prévias de leitura, como interação com jogos ou objetos com interface gamificada, pois os participantes apresentam certo grau de alfabetização visual (ALVES; TEIXEIRA, 2014). Isso porque as cores usadas de fundo na tela dos feedbacks podem ter transmitido uma resposta visual, em razão de o positivo/correto ser de cor verde e o negativo/ incorreto ser de cor vermelha. Outra possibilidade pode residir no fato de que não havia objetivos de leitura explícitos em relação aos feedbacks e, por essa razão, os sujeitos participantes podem ter desconsiderado sua leitura. Evidenciamos, assim, que o papel metacognitivo dos feedbacks não foi concretizado nesta atividade.

Ainda que representem um recorte limitado de sujeitos, bem como um retrato da realidade que, por si só, não revela a complexidade do processamento da compreensão, o relato do experimento aqui desenhado evidencia que os objetivos de leitura podem ter papel decisivo na estratégia de leitura escolhida pelos estudantes quando interagiram com o objeto digital de aprendizagem.

\section{Considerações finais}

O estudo apresentado teve como objetivo analisar o comportamento leitor de estudantes do $7^{\circ}$ ano na interação com um objeto digital de aprendizagem e examinar as estratégias de leitura utilizadas por eles. Para isso, abordou-se a concepção de leitura baseada na perspectiva da compreensão e da metacognição.

A partir dos dados coletados com o auxilio do software de captura de tela CamStudio, conclui-se que a estratégia de leitura linear foi a mais requerida pelos participantes do experimento, se analisarmos o total de tempo empregado para o desenvolvimento da atividade. Entretanto, ao refletirmos sobre o desempenho dos estudantes em particular, verificamos que: a) assim que encontraram as respostas para a tarefa, os estudantes saltavam com cursor do mouse indicando que a leitura do texto em si não era relevante; b) os participantes que logo iniciaram a leitura em saltos precisaram investir maior tempo em retomadas, a fim de encontrar a resposta à tarefa; e c) os feedbacks não foram lidos como esperávamos, o que revelou que a abordagem metacognitiva do objeto digital de aprendizagem, nesse experimento, não teve impacto na estratégia de leitura empregada pelos sujeitos participantes da atividade.

Mesmo que limitado, o estudo aqui desenhado já revela alguns insights para a definição de pesquisas futuras, que possam responder a outras perguntas, como, por exemplo: que tipo de enunciados devem ser propostos nas tarefas e atividades, a fim de garantir a definição de objetivos claros logo no início da leitura em contextos didáticos? Como dar maior visibilidade às estratégias metacognitivas de leitura, já que são elas que induzem à consciência e ao automonitoramento do percurso de leitura?

Como sugerimos no início deste texto, há ainda um grande percurso a ser trilhado no que diz respeito ao ensino da leitura para a formação de leitores hábeis, capazes de se valer de diferentes estratégias de compreensão que se adequem aos objetivos e aos propósitos de leitura. Parece-nos, porém, que compreender os modos de ler pode ser um bom ponto de partida para amenizar e facilitar esse percurso.

\section{Referências}

ALVES, M. M.; TEIXEIRA, O. Gamificação e objetos de aprendizagem: contribuições da gamificação para o design de objetos de aprendizagem. In: FADEL, L. M. et al. (org.). Gamificação na educação. São Paulo: Pimenta Cultural, 2014. p. 123-142.

BEDDIGTON, J. et al. The mental wealth of nations. Nature, London, n. 455, p. 1057-1060, 2008. https://doi. org/10.1038/4551057a

BRASIL. Relatório Brasil no PISA 2018: Versão Preliminar. Brasilia: Ministério da Educação (MEC); Instituto Nacional de Estudos e Pesquisas Educacionais Anísio Teixeira (INEP; Diretoria de Avaliação da Educação Básica (DAEB), 2018. Disponivel em: http://download. inep.gov.br/acoes_internacionais/pisa/documentos/2019/relatorio_PISA_2018_preliminar.pdf. Acesso em: 27 jul. 2020. 
COLTHEART, M. Modelando a leitura: a abordagem da dupla rota. In: SNOWLING, M. J.; HULME, C. (org.). A ciência da leitura. Porto Alegre: Penso, 2003. p. 24-41.

FORNECK, K. L.; FUCHS, J. T.; BERCH, M. E. Objetos digitais de aprendizagem para o ensino e a aprendizagem da leitura. Revista Linguistica, Rio de Janeiro, v. 11, n. 2, p. 208-228, 2015

INSTITUTO NACIONAL DE ESTUDOS E PESQUISAS EDUCACIONAIS ANISIO TEIXEIRA (INEP). Resumo Técnico: resultados do indice de desenvolvimento da Educação Básica. Brasília: INEP, 2017. Disponivel em: http://download.inep.gov.br/educacao_basica/ portal_ideb/planilhas_para_download/2017/ResumoTecnico_Ideb_2005-2017.pdf. Acesso em: 30 jul. 2020.

KATROCHVIL, C. F. Letramento e tecnologia: o aprendiz estratégico e crítico na era da informação. In: NASClMENTO, A. D.; HETKOWSKI, T. M. (org.). Educação e contemporaneidade: pesquisas cientificas e tecnológicas. Salvador: EDUFBA, 2009. p. 205-219

KINTSCH, W:; RAWSON, K. Compreensão. In: SNOWLING, M.; HULME, C. (org.). A ciência da leitura. Porto Alegre: Penso, 2013. p. 227-244.

KOL, S.; SCHCOLNIK, M. Enhancing screen-reading strategies. CALICO Journal, [s. l.], v. 18, n. 1, p. 67-80, 2000. https://doi.org/10.1558/cj.v18i1.67-80

LEFFA, V. J. Aspectos da leitura. Porto Alegre: Sagra, 1996.

MORAES, R. C. T. Ler e compreender textos em inglês: algumas estratégias. São Carlos: UAB UFSCAR, 2014.

MORAIS, J. Criar leitores para professores e educadores. Barueri: Manole, 2013.

PEREIRA, V. W. A predição na teia de estratégias de compreensão leitora. Revista Confluência, Rio de Janeiro, v. 1, p. 81-91, 2012. https://doi.org/10.17851/1983-3652.10.1.66-82

PEREIRA, V. W.; BARETTA, D.; SARAIVA, J. R. Compreensão, estratégias e aprendizagem no uso de um livro digital multimídia. RASAL Linguística, [s. L.], p. 117-135, 2017.

PEREIRA, V. W.; SANTOS, T. V. Consciência linguística no uso de estratégias de leitura na escola, em tecnologia virtual e tecnologia não virtual. Texto Livre, [s. l.], v. 10, n. 1, p. 66-82, jan./jun. 2017.

PERFETTI, C. A.; LANDI, N.; OAKHILL, J. A aquisição da habilidade de compreensão da leitura. In: SNOWLING, M. J.; HULME, C. (org.). A ciência da leitura. Porto Alegre: Penso, 2013. p. 245- 264.

REPOSITÓRIO DE OBJETOS DE APRENDIZAGEM DA UNIVATES (ROAU). Disponivel em: www.univates.br/ roau. Acesso em: 27 jul. 2020.

SOLÉ, I. Estratégias de Leitura. 6. ed. Porto Alegre: Artmed, 1998.

ZACHARIAS, V. R. C. Letramento Digital: desafios e possibilidades para o ensino. In: COSCARELLI, C. V. (org.). Tecnologias para aprender. São Paulo: Parábola Editorial, 2016. p. 16-19.

\section{Kári Lúcia Forneck}

Doutora em Linguistica pela Pontifícia Universidade Católica do Rio Grande do Sul (PUCRS), em Porto Alegre, RS, Brasil. Docente do Curso de Letras e do Programa de Pós-Graduação em Ensino da Universidade do Vale do Taquari (Univates), em Lajeado, RS, Brasil.

\section{Silvana Neumann Martins}

Doutora em Educação pela Pontifícia Universidade Católica do Rio Grande do Sul Universidade Católica do Rio Grande do Sul (PUCRS), em Porto Alegre, RS, Brasil. Docente do Programa de Pós-Graduação em Ensino da Universidade do Vale do Taquari (Univates), em Lajeado, RS, Brasil.

\section{Carolina Taís Werlang}

Graduanda em Letras pela Universidade do Vale do Taquari (Univates), em Lajeado, RS, Brasil; bolsista de Iniciação Científica pela Universidade do Vale do Taquari (Univates), em Lajeado, RS, Brasil.

\section{Róger Sullivan Faleiro}

Mestrando pelo Programa de Pós-Graduação em Ensino, da Universidade do Vale do Taquari (Univates), em Lajeado, RS, Brasil. Bolsista Integral de Pós-Graduação pela Coordenação de Aperfeiçoamento de Pessoal de Nível Superior (Capes).

\section{Pâmela Lopes Vicari}

Mestranda em Linguística pela Universidade Federal de Santa Catarina (UFSC), em Florianópolis, SC, Brasil.

\section{Keylliane de Sousa Martins}

Mestranda pelo Programa de Pós-Graduação em Ensino pela Universidade do Vale do Taquari (Univates), em Lajeado, RS, Brasil. Docente do Instituto Federal de Educação do Maranhão (IFMA), em Itapecuru Mirim, MA, Brasil.

\section{Endereço para correspondência}

Kári Lúcia Forneck

Universidade do Vale do Taquari

Avenida Avelino Talini, 171, prédio 2, sala 336

Bairro Universitário, 95880000

Lajeado, RS, Brasil 